\title{
A-01 Metals in Stormwater Runoff Evaluation
}

by

L. L. Eldridge

Westinghouse Savannah River Company

Savannah River Site

Aiken, South Carolina 29808

DOE Contract No.

This paper was prepared in connection with work done under the above contract number with the U.S. Department of Energy. By acceptance of this paper, the publisher and/or recipient acknowledges the U. S. Government's right to retain a nonexclusive, royalty-free license in and to any copyright covering this paper, along with the right to reproduce and to authorize others to reproduce all or part of the copyrighted paper. 



\section{DISCLAIMER}

Portions of this document may be illegible electronic image products. Images are produced from the best available original document. 


\section{A-01 METALS IN STORMWATER RUNOFF EVALUATION}

\section{EXECUTIVE SUMMARY}

As a part of the A-01 investigation required by the NPDES permit, an investigation was performed to ascertain the concentrations of metals specifically copper $(\mathrm{Cu})$, lead $(\mathrm{Pb})$, and zinc $(\mathrm{Zn})$ in stormwater being discharged through the outfall. This information would indicate whether all water being discharged would have to be treated or if only a portion of the discharged stormwater would have to be treated.

A study was designed to accomplish this. The first goal was to determine if the metal concentrations increased, decreased, or remained the same as flow increased during a rain event. The second goal was to determine if the concentrations in the storm water were due to dissolved. The third goal was to obtain background data to ascertain if effluent credits could be gained due to naturally occurring metals.

Samples from this study were analyzed and indicate that the copper and lead values increase as the flow increases while the zinc values remain essentially the same regardless of the flow rate. Analyses of samples for total metals, dissolved metals, TSS, and metals in solids was complicated because in all cases metals contamination was found in the filters themselves. Some conclusions can be derived if this problem is taken into account when analyzing the data. Copper concentrations in the total and dissolved fractions as well as the TSS concentrations followed the hydrograph at this outfall but the copper in solids concentration appeared to peak in the first flush and decline to nondetectable rapidly over the course of the storm event. Lead was present in the total analysis but not present in the dissolved fraction or the solids fraction of the samples. The data for zinc was interesting in that the dissolved fractions were higher than the total fraction in three out of four samples. This is probably due to the high zinc concentrations on the filters being transferred to the dissolved faction of the sample. Analysis of background samples indicate that there are concentrations of lead and zinc in stormwater runoff due to naturally occurring concentrations or to roadway runoff. This is not the case with the Copper concentrations. Analysis indicates that there is no detectable copper concentrations in the background water analyzed.

This study indicates that all the water discharged through the A-01 outfall including the stormwater should be included in calculations for wetland or treatment facility sizing. 


\section{PROJECT DESCRIPTION}

To ascertain the quantity of metals in stormwater at the A-01 outfall, an Isco sequential sampler, rain gauge, and flow meter was set up at the outfall. This equipment was programmed to collect samples when a rain event occurred and the water elevation increased a specific amount. The system then collected an aliquot of sample at each time a specified quantity of water was discharged through the outfall. The stripchart of the flow meter was set up to record the headheight of water and record when each sample was collected. This allowed a specific flowrate to be associated with each sample. The individual samples were then analyzed and the data recorded. Data from seven storm events were evaluated and a need to discriminate between the total and dissolved fractions became evident. To accomplish this, samples were collected in the same manner but analyzed in a different manner. Each sample aliquot was split and one portion preserved and analyzed for total metals. The other portion was filtered and the resulting filter weighed for a total suspended solids analysis. The filter and preserved filtrate were then analyzed for metals. This analytical technique gave the following results: the total quantity of metals in the sample in $\mathrm{mg} / \mathrm{l}$, the amount of dissolved metals in the sample in $\mathrm{mg} / \mathrm{l}$, the total suspended solids in the sample, and the quantity of metals in solids in the sample in $\mathrm{mg} / \mathrm{kg}$. A final portion of the project involved a background location for the same metals to ascertain if these metals exist in the environment naturally and in what quantities. A location was chosen in the Tims Branch drainage area and background samples take. This sample point was located on SRS road 1 approximately 100 yards north east of the junctions of SRS roads 1 and 1A where a dry watercourse which drains to Tims Branch crosses under SRS road 1. A composite sampler was set up at this point and samples collected. Due to an equipment malfunction, both a grab was taken on the first day of the storm event and a composite was taken on the second day of the storm event after the equipment was repaired. These samples were analyzed for total metals, dissolved metals, metals in the solids and total suspended solids. Data from all samples are given in the following section. 


\section{RESULTS}

\section{Copper}

The total copper analyses given in the table below indicate that the concentrations increase as the flow increases. This is illustrated in the accompanying graph. The X-axis is an instantaneous flowrate in million gallons per day (MGD) and the $y$-axis represents the copper concentrations in $\mathrm{mg} / \mathrm{l}$.

$\begin{array}{llllll}\mathrm{Cu} & \text { Flow } & \mathrm{Cu} & \text { Flow } & \mathrm{Cu} & \text { Flow } \\ \mathrm{Mg} / \mathrm{L} & \mathrm{MGD} & \mathrm{Mg} / \mathrm{L} & \mathrm{MGD} & \mathrm{Mg} / \mathrm{L} & \mathrm{MGD} \\ 0.0530 & 0.1355 & 0.0550 & 5.7558 & 0.2700 & 51.2912 \\ 0.0930 & 0.1355 & 0.0360 & 6.4787 & 0.1480 & 53.1042 \\ 0.0460 & 0.1355 & 0.0560 & 6.7273 & 0.1310 & 56.8595 \\ 0.0600 & 0.3373 & 0.0620 & 7.2472 & 0.1190 & 58.8028 \\ 0.0240 & 0.6476 & 0.0260 & 7.6683 & 0.2960 & 60.7462 \\ 0.0640 & 0.8036 & 0.1780 & 7.6683 & 0.1090 & 60.7462 \\ 0.0330 & 0.9218 & 0.0990 & 7.8052 & 0.2760 & 62.4303 \\ 0.0520 & 1.0746 & 0.1020 & 8.3838 & 0.1410 & 64.7015 \\ 0.1000 & 1.2336 & 0.0550 & 8.8356 & 0.2430 & 66.7445 \\ 0.0480 & 1.2336 & 0.1310 & 10.3367 & 0.1310 & 66.7445 \\ 0.0750 & 1.6161 & 0.0240 & 14.5865 & 0.2470 & 68.7789 \\ 0.1690 & 1.6762 & 0.0210 & 18.5567 & 0.1680 & 68.7789 \\ 0.0330 & 1.7500 & 0.0240 & 23.8406 & 0.2070 & 70.8936 \\ 0.0550 & 1.7938 & 0.1910 & 25.5405 & 0.1800 & 70.8936 \\ 0.0450 & 2.2576 & 0.1480 & 29.9748 & 0.2190 & 72.9732 \\ 0.0940 & 2.5177 & 0.1750 & 30.6486 & 0.1630 & 72.9732 \\ 0.0510 & 3.4013 & 0.2510 & 30.6486 & 0.1820 & 75.1134 \\ 0.0500 & 3.4013 & 0.0730 & 32.1704 & 0.1500 & 75.1134 \\ 0.0430 & 3.7406 & 0.0270 & 32.9174 & & \\ 0.0600 & 4.7122 & 0.1850 & 32.9174 & & \\ 0.0520 & 4.8808 & 0.1330 & 39.1770 & & \\ 0.0510 & 5.3090 & 0.1290 & 45.9239 & & \end{array}$


Analysis of background samples for copper indicate that with one exception which is at the detection limit copper is not present. This data is given below. The samples were split in the lab for quality control reasons and both composite and grab samples were duplicated.

$\begin{array}{lllll}\text { Sample Type } & \begin{array}{l}\text { Total } \mathrm{Cu} \\ \mathrm{Mg} / \mathrm{L}\end{array} & \begin{array}{l}\text { Dissolved } \mathrm{Cu} \\ \mathrm{Mg} / \mathrm{L}\end{array} & \begin{array}{l}\mathrm{Cu} \text { in TSS } \\ \mathrm{Mg} / \mathrm{Kg}\end{array} & \begin{array}{c}\mathrm{TSS} \\ \mathrm{Mg} / \mathrm{L}\end{array} \\ & & & & \\ \text { Grab } & 0.0050 & <0.005 & <0.250 & 69.0 \\ \text { Grab } & <0.005 & <0.005 & <0.250 & 87.0 \\ \text { Composite } & <0.005 & <0.005 & <0.250 & 18.0 \\ \text { Composite } & <0.005 & <0.005 & <0.250 & 25.0\end{array}$

Several quality control samples were run with the analyses to determine if the analytical method introduced copper to the analytical results. During the A-01 sampling for total, dissolved and sediment copper analyses, deionized water was treated in the same manner as the sample and analyzed. A filter that had been prepared for TSS analysis by seating it in the crucible with $20 \mathrm{mls}$ of deionized water was also analyzed. These results are given below. During the background analyses, the same procedure was followed except that an unprepared filter was used and all QA samples were done in duplicate. A complicating factor occurred when three of the filters used as QA for the background samples showed measurable quantities of copper. This would become important if there were measurable quantities of copper in the dissolved or solid fractions of the analyses. This is not the case with the copper analyses and this contamination does not affect interpretation of the analytical results. The generated Quality control data are also listed below.

QA Data from A-01 Sample

\section{Deionized Water Data}

$\begin{array}{lll} & \text { Diss. } & \text { Filter } \\ & \mathrm{Mg} / \mathrm{L} & \mathrm{Mg} / \mathrm{Kg} \\ \mathrm{Cu} & <0.005 & <12.4 \\ \mathrm{Cu} & <0.005 & <13.3\end{array}$

Filter Data

$\begin{array}{ll}\text { TSS } & \text { Filter } \\ \mathrm{Mg} / \mathrm{L} & \mathrm{Mg} / \mathrm{Kg} \\ <1.0 & \mathrm{Cu} \quad<12.2 \\ <1.0 & \mathrm{Cu}<15.0\end{array}$

Quality Control From Background Samples

$\begin{array}{llll}\text { Filter-No Preparation } & \mathrm{Cu} & \text { Blank Filter } & \mathrm{Cu} \\ & \mathrm{Mg} / \mathrm{Kg} & & \mathrm{Mg} / \mathrm{Kg} \\ \text { TB- Filter }-1 & 12.40 & \text { TB- Blk Filter }-1 & 13.20 \\ \text { TB- Filter }-2 & <0.25 & \text { TB- Blk Filter }-2 & <.25 \\ & & & \\ \text { Filter -Preparation Only } & \mathrm{Cu} & \text { Filtered H20 } & \mathrm{Cu} \\ & \mathrm{Mg} / \mathrm{Kg} & & \mathrm{Mg} / \mathrm{L} \\ \text { TB- Filter }-1 & 12.40 & \text { TB-Blk Dissolved-1 } & <0.005 \\ \text { TB- Filter }-2 & <0.25 & \text { TB-Blk Dissolved-2 } & <0.005 \\ \text { Lead } & & & \end{array}$


The total lead analyses indicate that during a storm event, lead values increase as the flow values increase. This is illustrated in the following Table and accompanying graph. The $\mathrm{X}$-axis is an instantaneous flowrate in million gallons per day (MGD) and the $\mathrm{Y}$-axis represents the lead concentrations in $\mathrm{mg} / \mathrm{l}$.

$\begin{array}{llll}\text { Flow } & \mathrm{Pb} & \text { Flow } & \mathrm{Pb} \\ \text { MGD } & \mathrm{Mg} / \mathrm{L} & \mathrm{MGD} & \mathrm{Mg} / \mathrm{L} \\ 0.1355 & 0.0040 & 14.5865 & 0.0030 \\ 0.1355 & 0.0040 & 18.5567 & 0.0050 \\ 0.1355 & 0.0090 & 23.8406 & 0.0030 \\ 0.3373 & 0.0040 & 25.5405 & 0.0350 \\ 0.6476 & 0.0050 & 29.9748 & 0.0330 \\ 0.8036 & 0.0040 & 30.6486 & 0.0350 \\ 0.9218 & 0.0060 & 30.6486 & 0.0480 \\ 1.0746 & 0.0030 & 32.1704 & 0.0110 \\ 1.2336 & 0.0040 & 32.9174 & 0.0030 \\ 1.2336 & 0.0090 & 32.9174 & 0.0410 \\ 1.6161 & 0.0050 & 39.1770 & 0.0170 \\ 1.6762 & 0.0250 & 45.9239 & 0.0170 \\ 1.7500 & 0.0080 & 51.2912 & 0.0320 \\ 1.7938 & 0.0550 & 53.1042 & 0.0200 \\ 2.2576 & 0.0040 & 56.8595 & 0.0110 \\ 2.5177 & 0.0060 & 58.8028 & 0.0200 \\ 3.4013 & 0.0040 & 60.7462 & 0.0180 \\ 3.4013 & 0.0050 & 60.7462 & 0.0450 \\ 3.7406 & 0.0040 & 62.4303 & 0.0330 \\ 4.7122 & 0.0060 & 64.7015 & 0.0220 \\ 4.8808 & 0.0040 & 66.7445 & 0.0210 \\ 6.4787 & 0.0060 & 66.7445 & 0.0410 \\ 6.7273 & 0.0050 & 68.7789 & 0.0250 \\ 7.2472 & 0.0070 & 68.7789 & 0.0430 \\ 7.6683 & 0.0110 & 70.8936 & 0.0320 \\ 7.6683 & 0.0260 & 70.8936 & 0.0340 \\ 7.8052 & 0.0080 & 72.9732 & 0.0260 \\ 8.3838 & 0.0090 & 72.9732 & 0.0280 \\ 8.8356 & 0.0070 & 75.1134 & 0.0230 \\ 10.3367 & 0.0230 & 75.1134 & 0.0350 \\ & & & \end{array}$




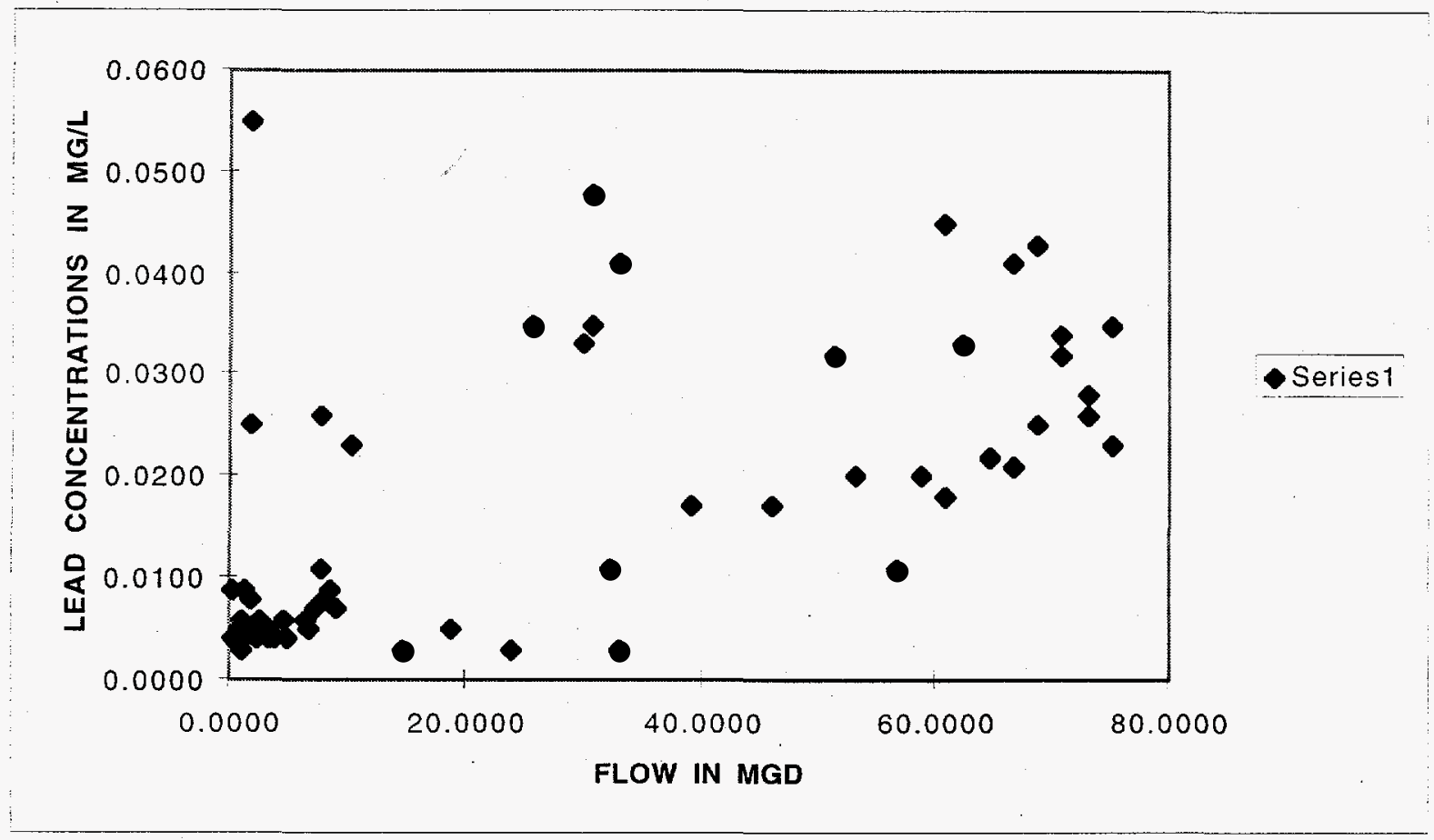

The results generated by the stormwater samples analyzed for total metals, dissolved metals, TSS, and metals in the sediment indicate that lead is present in the total analyses but in only one case present in the dissolved fraction. The total lead quantities also follow flow quantities though in small increments. No lead was found in the solids fraction analyzed. These data are given in the following table;

\begin{tabular}{|c|c|c|c|c|c|c|}
\hline & & Total & Diss. & TSS & Filter & Flow \\
\hline & & $\mathrm{Mg} / \mathrm{L}$ & $\mathrm{Mg} / \mathrm{L}$ & $\mathrm{Mg} / \mathrm{L}$ & $\mathrm{Mg} / \mathrm{Kg}$ & MGD \\
\hline A-01-1 & $\mathrm{Pb}$ & 0.004 & 0.005 & 8.0 & $<12.3$ & 1.9 \\
\hline A-01-2 & $\mathrm{Pb}$ & 0.006 & $<0.003$ & 85.0 & $<12.1$ & 25.4 \\
\hline A-01-3 & $\mathrm{Pb}$ & 0.006 & $<0.003$ & 35.0 & $<12.0$ & 20.9 \\
\hline$A-01-4$ & $\mathrm{~Pb}$ & 0.004 & $<0.003$ & 16.0 & $<12.3$ & 5.6 \\
\hline
\end{tabular}


Analysis of background samples for lead are given below. The samples were split in the lab for quality control reasons and both composite and grab samples were duplicated. Lead was found in both the grab and composite background samples in both the total and dissolved fractions at levels that exceed the monthly average limit $(0.005 \mathrm{mg} / \mathrm{l})$ proposed for the A-01 outfall.

$\begin{array}{lllll}\text { Sample Type } & \begin{array}{l}\text { Total } \mathrm{Pb} \\ \mathrm{Mg} / \mathrm{L}\end{array} & \begin{array}{l}\text { Dissolved } \mathrm{Pb} \\ \mathrm{Mg} / \mathrm{L}\end{array} & \begin{array}{l}\mathrm{Pb} \text { in TSS } \\ \mathrm{Mg} / \mathrm{Kg}\end{array} & \begin{array}{c}\mathrm{TSS} \\ \mathrm{Mg} / \mathrm{L}\end{array} \\ \text { Grab } & 0.012 & 0.008 & 7.31 & 69.0 \\ \text { Grab } & 0.009 & 0.004 & 8.90 & 87.0 \\ \text { Composite } & 0.031 & 0.006 & 2.10 & 18.0 \\ \text { Composite } & 0.006 & 0.005 & 4.58 & 25.0\end{array}$

Several quality control samples were run to determine if the analytical method introduced lead into the analytical results. Deionized water was treated in the same manner as the sample and analyzed. A filter that had been prepared for TSS analysis by seating it in the crucible with $20 \mathrm{mls}$ of deionized was also analyzed. These results are given below. During the background analyses, the same procedure was followed except that an unprepared filter was also analyzed and all QA samples were done in duplicate. Those results are also listed below. The data indicates that there is lead in the filters used in the dissolved and solids analyses and though none appears in any of the liquid fraction results, all positive results for dissolved and solids fractions should be viewed as suspect.

\section{Deionized Water Data}

$$
\text { Diss. }
$$

$\mathrm{Mg} / \mathrm{L}$

$\mathrm{Pb}<0.003$

$\mathrm{Pb}<0.003$

Filter

$\mathrm{Mg} / \mathrm{Kg}$

12.400

$<13.3$
Filter Data

$\begin{array}{ll}\text { TSS } & \text { Filter } \\ \mathrm{Mg} / \mathrm{L} & \mathrm{Mg} / \mathrm{Kg} \\ <1.0 & \mathrm{~PB} \quad<12.2 \\ <1.0 & \mathrm{~PB} \quad<15.0\end{array}$

$\begin{array}{llll}\text { Filter-No Preparation } & \mathrm{Pb} & \text { Blank Filter } & \begin{array}{l}\mathrm{Pb} \\ \mathrm{Mg} / \mathrm{Kg}\end{array} \\ \text { TB-Filter-1 } & \mathrm{Mg} / \mathrm{Kg} & & 1.65 \\ \text { TB- Filter }-2 & 1.33 & \text { TB- Blk Filter }-1 & 2.40 \\ & 1.74 & \text { TB-Blk Filter }-2 & \\ \text { Filter-Preparation Only } & \mathrm{Pb} & \text { Filtered } \mathrm{H} 20 & \mathrm{~Pb} \\ & \mathrm{Mg} / \mathrm{Kg} & & \mathrm{Mg} / \mathrm{L} \\ \text { TB- Filter }-1 & 1.52 & \text { TB- Blk Dissolved-1 } & <0.003 \\ \text { TB- Filter }-2 & 2.01 & \text { TB- Blk Dissolved }-2 & <0.003\end{array}$




\section{Zinc}

The total zinc analyses indicates that during a storm event, zinc values remain essentially the same as the flow values increase. This is illustrated in the following Table and accompanying graph. The X-axis is an instantaneous flowrate in million gallons per day (MGD) and the $\mathrm{Y}$-axis represent the lead concentrations in $\mathrm{mg} /$.

$\begin{array}{llll}\text { Flow } & \text { Zn } & \text { Flow } & \mathrm{Zn} \\ \text { MGD } & \mathrm{Mg} / \mathrm{L} & \mathrm{MGD} & \mathrm{Mg} / \mathrm{L} \\ 0.1355 & 0.2140 & 10.3367 & 0.2730 \\ 0.1355 & 0.5910 & 14.5865 & 0.1110 \\ 0.1355 & 0.3280 & 18.5567 & 0.1050 \\ 0.3373 & 0.2300 & 23.8406 & 0.0990 \\ 0.6476 & 0.0470 & 25.5405 & 0.3780 \\ 0.8036 & 0.2470 & 29.9748 & 0.4880 \\ 0.9218 & 0.8640 & 30.6486 & 0.2490 \\ 1.0746 & 0.3060 & 30.6486 & 0.3240 \\ 1.2336 & 0.4150 & 32.1704 & 0.2580 \\ 1.2336 & 0.3760 & 32.9174 & 0.1150 \\ 1.6161 & 0.2280 & 32.9174 & 0.4310 \\ 1.6762 & 0.1350 & 39.1770 & 0.2620 \\ 1.7500 & 0.1030 & 45.9239 & 0.2800 \\ 1.7938 & 0.3620 & 51.2912 & 0.2830 \\ 2.2576 & 0.3520 & 53.1042 & 0.2650 \\ 2.5177 & 0.2340 & 56.8595 & 0.2700 \\ 3.4013 & 0.3560 & 58.8028 & 0.1910 \\ 3.4013 & 0.3450 & 60.7462 & 0.5060 \\ 3.7406 & 0.3390 & 60.7462 & 0.1830 \\ 4.7122 & 0.1450 & 62.4303 & 0.5300 \\ 4.8808 & 0.3790 & 64.7015 & 0.3410 \\ 5.3090 & 0.3480 & 66.7445 & 0.3780 \\ 5.7558 & 0.3460 & 66.7445 & 0.3640 \\ 6.4787 & 0.1740 & 68.7789 & 0.4780 \\ 6.7273 & 0.3220 & 68.7789 & 0.3760 \\ 7.2472 & 0.2670 & 70.8936 & 0.4290 \\ 7.6683 & 0.0380 & 70.8936 & 0.5040 \\ 7.6683 & 2.2300 & 72.9732 & 0.4740 \\ 7.8052 & 0.3160 & 72.9732 & 0.3640 \\ 8.3838 & 0.3810 & 75.1134 & 0.3650 \\ 8.8356 & 0.1150 & 75.1134 & 0.2800\end{array}$




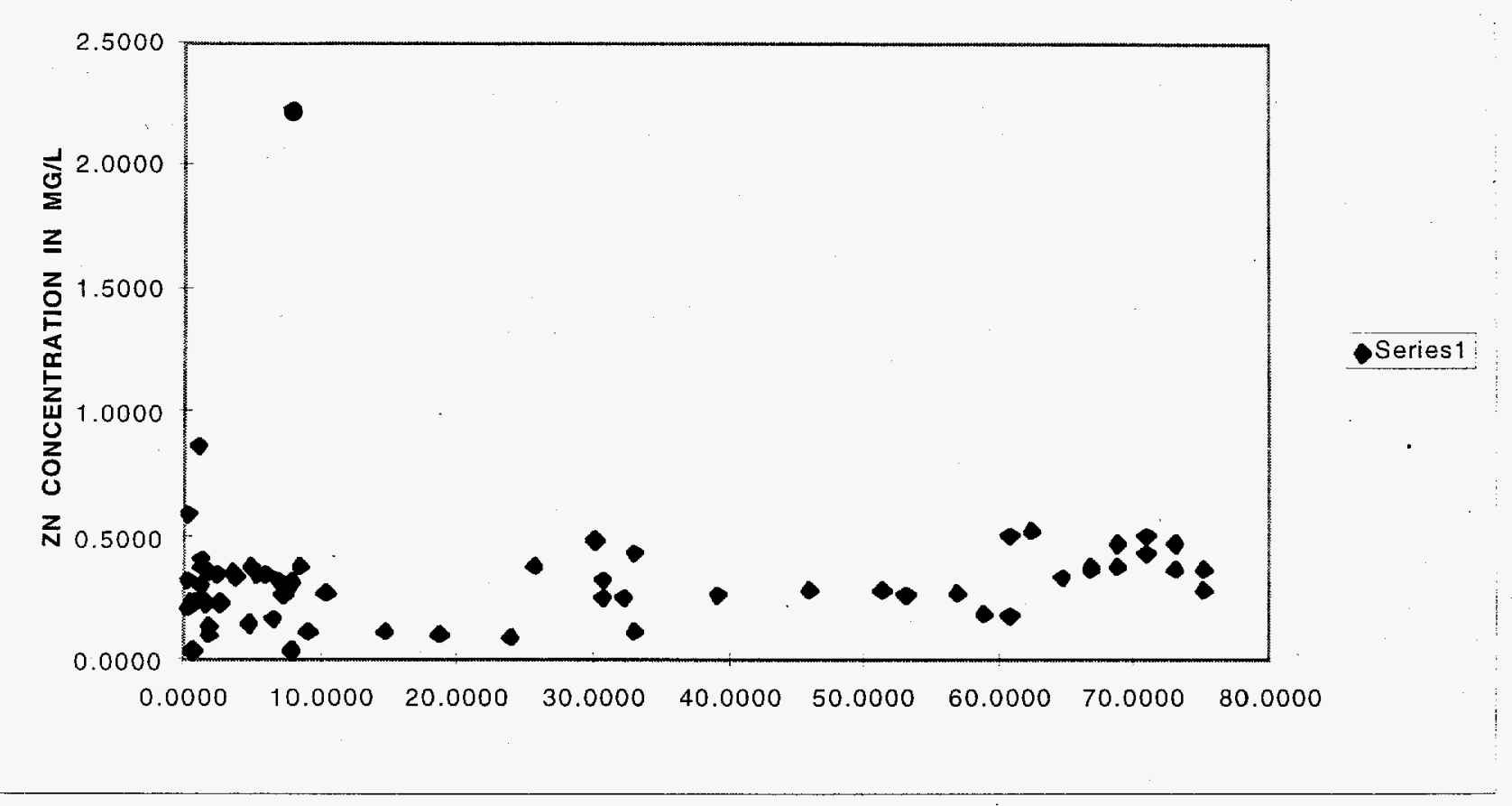

The results generated by the stormwater samples taken and analyzed for total metals, dissolved metals, TSS, and metals in the sediment are given in the following table. It is interesting to note that in three out of four samples that the dissolved fraction contains more zinc than the total fraction.

$\begin{array}{lllllll} & & \begin{array}{c}\text { Total } \\ \mathrm{Mg} / \mathrm{L}\end{array} & \begin{array}{c}\text { Diss. } \\ \mathrm{Mg} / \mathrm{L}\end{array} & \begin{array}{c}\mathrm{TSS} \\ \mathrm{Mg} / \mathrm{L}\end{array} & \begin{array}{l}\text { Filter } \\ \mathrm{Mg} / \mathrm{Kg}\end{array} & \begin{array}{c}\text { Flow } \\ \mathrm{MGD}\end{array} \\ \mathrm{A}-01-1 & \mathrm{Zn} & 0.053 & 0.024 & 8.000 & 168.000 & 1.9 \\ \mathrm{~A}-01-2 & \mathrm{Zn} & 0.191 & 0.216 & 85.000 & 231.000 & 25.4 \\ \mathrm{~A}-01-3 & \mathrm{Zn} & 0.177 & 0.707 & 35.000 & 155.000 & 20.9 \\ \mathrm{~A}-01-4 & \mathrm{Zn} & 0.106 & 0.115 & 16.000 & 189.000 & 5.6\end{array}$


Analysis of background samples for zinc are given below. The samples were split in the lab for quality control reasons and both composite and grab samples were duplicated. Please note that three out of four dissolved analytical results are greater than the total metals results.

$\begin{array}{lllll}\text { Sample Type } & \begin{array}{l}\text { Total Zn } \\ \mathrm{Mg} / \mathrm{L}\end{array} & \begin{array}{l}\text { Dissolved Zn } \\ \mathrm{Mg} / \mathrm{L}\end{array} & \begin{array}{l}\mathrm{Zn} \text { in TSS } \\ \mathrm{Mg} / \mathrm{Kg}\end{array} & \begin{array}{c}\mathrm{TSS} \\ \mathrm{Mg} / \mathrm{L}\end{array} \\ \mathrm{Grab} & 0.039 & 0.037 & 126.0 & 69.0 \\ \text { Grab } & 0.059 & 0.067 & 135.0 & 87.0 \\ \text { Composite } & 0.045 & 0.105 & 151.0 & 18.0 \\ \text { Composite } & 0.030 & 0.050 & 135.0 & 25.0\end{array}$

Several quality control samples were run to determine if the analytical method introduced zinc into the analytical results. Deionized water was treated in the same manner as the sample and analyzed. A filter that had been prepared for TSS analysis by seating it in the crucible with $20 \mathrm{mls}$ of deionized was also analyzed. These results are given below. During the background analyses, the same procedure was followed except that an unprepared filter was also analyzed and all QA samples were done in duplicate. These results are given below. Those results are also listed below. Please note that zinc concentrations are found in all phases of the quality control process. This may explain why dissolved fractions are higher than the total concentrations in the stormwater and background samples.

$\begin{array}{llll} & \text { Diss. } & \text { Filter } & \text { TSS } \\ & \mathrm{Mg} / \mathrm{L} & \mathrm{Mg} / \mathrm{Kg} & \mathrm{Mg} / \mathrm{L} \\ \mathrm{Zn} & <0.005 & 89.400 & <1.0 \\ \mathrm{Zn} & <0.005 & 126.000 & <1.0\end{array}$

$\begin{array}{ll} & \text { Filter } \\ & \mathrm{Mg} / \mathrm{Kg} \\ \mathrm{Zn} & 128.000 \\ \mathrm{Zn} & 84.600\end{array}$

Filter-No Preparation

TB-Filter-1

TB-Filter-2

Filter-Preparation Only

TB-Filter-1

TB-Filter-2
$\mathrm{Zn}$

$\mathrm{Mg} / \mathrm{Kg}$

184.000

139.0000

$\mathrm{Zn}$

$\mathrm{Mg} / \mathrm{Kg}$

83.400

193.00
Blank filter

TB- Blk Filter-1

TB-Blk Filter-2

Filtered H20

TB- Blk Dissolved-1

TB- Blk Dissolved-2
$\mathrm{Zn}$

$\mathrm{Mg} / \mathrm{Kg}$

83.0000

153.000

$\mathrm{Zn}$

$\mathrm{Mg} / \mathrm{L}$

0.023

0.051 


\section{CONCLUSION}

\section{Copper}

The data indicates that the copper values increase as the flow increases in the liquid samples analyzed. This is true of both total and dissolved fractions. The samples analyzed for TSS indicated that the solids values also increased and decreased with flow whereas the metals found on the filters in solid form decreased over the duration of the storm. This would indicate that the copper is being resuspended in the first flush of the storm event rather than throughout the storm event. Background water samples indicated no detectable copper concentrations evident. This would mean no background credits could be used in calculation of copper limits for this outfall.

\section{Lead}

QA data indicate that the all solids results should be discounted due to $\mathrm{Pb}$ contamination inherent in the filters and that positive dissolved data should be reviewed carefully prior to acceptance though contamination is not evident in the QA samples run. The total lead data indicates that generally as flow increases the concentration of lead increases. This is ameliorated to a large degree by the amount of lead found in the background samples. The maximum amount of lead found in the stormwater samples taken at the A-01 outfall was $0.055 \mathrm{mg} / \mathrm{l}$ and the maximum amount of lead analyzed in an aliquot of the background sample was $0.031 \mathrm{mg} / \mathrm{l}$. This comparison is made only to indicate that lead is naturally found in the environment at levels that are in excess of the average limit in the permit. This would mean that during rain events, lead level elevation will be contributed to by natural runoff.

\section{Zinc}

The data indicates that $\mathrm{Zn}$ concentrations remain essentially the same regardless of flow. It was interesting to note that in comparing the total and dissolved fractions of the four samples taken for this purpose that the dissolved fraction was higher than the total fraction. This may be caused by contamination of the dissolved fractions by the filters which contained significant quantities of zinc.

The QA data shows the filtered deionized water fraction as having $0.023 \mathrm{mg} / \mathrm{l}$ and $0.051 \mathrm{mg} / \mathrm{l} \mathrm{Zn}$ concentrations. The total analyses for $\mathrm{Zn}$ in the background samples does indicate that it is present in the environment in quantities at levels $(0.131 \mathrm{mg} / \mathrm{l})$ approximately half that of the average effluent concentrations $(0.341 \mathrm{mg} / \mathrm{l})$ during a rain event. 